\title{
Variaçōes geográficas no ciclo de picada do Anopheles darlingi Root no Brasil
}

\author{
J. Derek Charlwood (*) \\ Jack Hayes (*)
}

\begin{abstract}
Resumo
O comportamento e as diferenças no ciclo do ataque do Anopheles darlingi Root, em três localidades diferentes brasileiras, foram comparadas e discutidas.
\end{abstract}

\section{INTRODUÇÃo}

Recentemente estudos têm mostrado que as espécies de Anopheles tendem a ser particularmente instáveis; o que antes havia sido considerado como uma única espécie tem, freqüentemente, se transformado num complexo de várias espécies estreitamente relacionadas (Wright \& Pal, 1967). Isto é particularmente importante para o epidemiologista de malárı uma vez que espécies cripticas, ou as subespécies, provavelmente se diferenciam em comportamento, o que pode afetar a capacidade vetorial das espécies. Por exemplo, A. nuneztovari Gabaldon é um vetor de malária na Venezuela (Scorza et al, 1976), mas no Brasil esta espécie não parece transmití-la. O progresso no uso de híbridos estéreis como agentes de controle pode ser, também, resultado das informações obtidas concernentes às relações entre subespécies de mosquito (Davidson 1974).

A despeito do fato de ser o maior vetor de malária na América do Sul, poucos trabalhos têm sido feitos sobre a biologia básica de Anopheles darlingi Root. Especificamente, nenhum estudo correlacionando sua distribuição geográfica com suas variaçỏes comportamentais foi ainda publicado. Este trabalho relata a variação no ciclo de picadas em três áreas distintas no Brasil; discutir-se-á, também, as possíveis implicações desta variabilidade em trabalhos futuros sobre 0 anofelíno vetor.

\section{MÉTODOS}

Capturas peridomiciliárias de 12 horas de picadas, usando isca humana, foram feitas em três locais no Brasil. Os lugares foram, de Norte a Sul: em Uauaris, no Território de Roraima; km 137 da rodovia Manaus-Boa Vista (BR 174), no Amazonas, e em Aripuanã, no Mato Grosso (Fig. 1). A isca humana dormiu em uma rede na varanda de uma casa de palha em cada lugar. Estas casas eram semelhantes e situadas perto (cerca de 3000 metros) dos criadouros. Os mosquitos que vinham para se alimentar foram capturados pelo coletor, com um aspirador. Os coletores eram normalmente trocados a cada três horas, e as coletas feitas em, pelo menos, três noites, das 18:00 horas às 06:00 horas da manhã. Os mosquitos

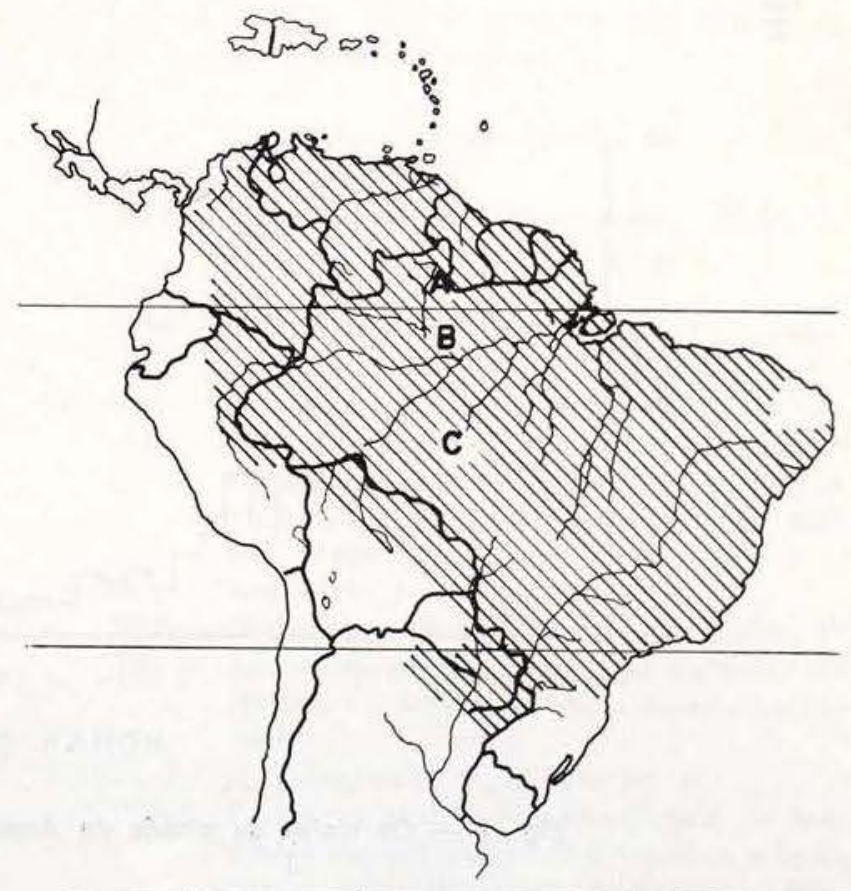

Fig. 1 - Distribuição geográfica do Anopheles darlingi no Brasil, segundo Forattini (1962), e as localizaçōes das estações de coletas: A) Aauaris - Roraima $0408^{\prime} \mathrm{N}$ $640^{\circ}{ }^{\prime} \mathrm{W}$; B) $\mathrm{Km} 137$ - BR-174 - Amazonas 01050'S 60030 'W: C) Aripuanã - Mato Grosso 10011'S 59049'W.

(") - Instituto Nacional de Pesquisas da Amazônia, Manaus. 

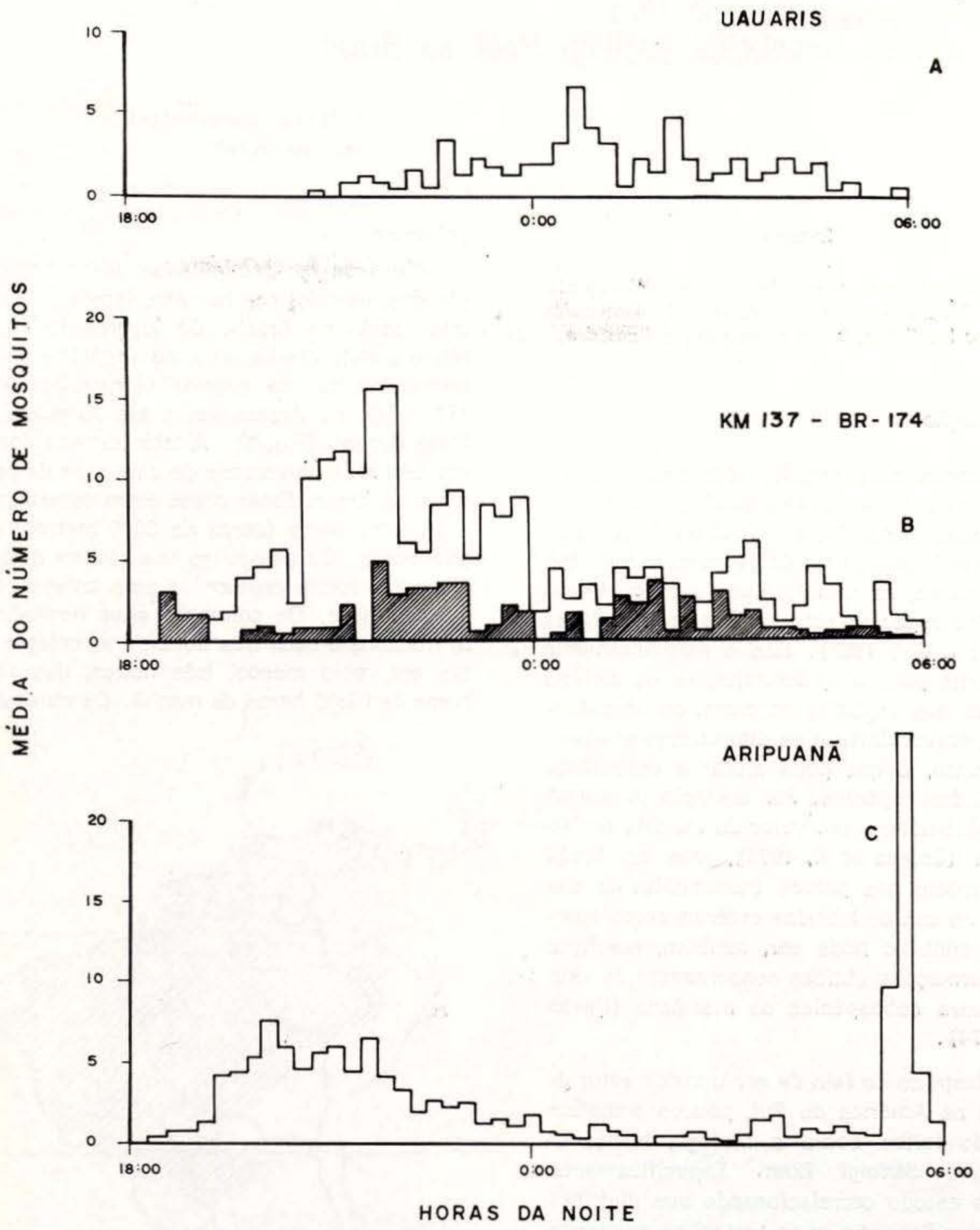

Fig. 2 - Os ciclos de picada do Anopheles darlingi nas três áreas.
A) Coletada em 01/04/77; 02/04/77 e 05/04/77 Total coletado 193
Média $\quad 64.3$ cada noite
B) Gráfico riscado. 04/07/77 a 06/07/77. Total 218 Média
73.67 cada noite
B) Gráfico claro.
Coletado em 29/03/77 a 01/04/77
Total
670
Média
223.3 cada noite
C) Coletada em $16 / 03 / 77$ a $21 / 03 / 77$
Total
Média
806
134.34 cada noite 
eram separados em períodos de quinze em quinze minutos e a média para cada noite de cada quinze minutos calculada (Fig. 2).

\section{RESUltados E DISCUSSÃo}

A. darlingi tem uma ampla distribuição geográfica e as três amostras cobrem grande parte de sua distribuição de Norte a Sul. Entretanto, os resultados apresentam um ciclo da atividade de picada demonstravelmente diferente em cacia dos três locais onde foram feitas as coletas. O pico de atividade ocorre depois da meia noite em Uauaris, enquanto que, tanto no km 137 como no Aripuanã, o pico primário ocorre entre às 21:00 e às 23:00 horas. Resultados das capturas anuais mos. traram que este ciclo de ataque não muda, embora a densidade da população tenha mudado (Hayes \& Chariwood 1978). A variante mais notável entre as três áreas foi o pico pronunciado de uma atividade matinal que ocorreu em Aripuanã. Este foi tão intenso que $26,4 \%$ da caputra total foi feita num período entre $05: 35$ à $05: 45$ horas. Este padrão continucu no ano seguinte. Neste horário já era dia e uma onda de Simulium sp. (possivelmente $S$. major), que pica durante o dia, apareceu simultaneamente ao pico do A. darlingi. Este ápice de picada do $A$. darlingi também ocorreu dentro das casas, onde não foram feitas capturas quantitativas.

Em nenhuma das áreas foram encontradas Anophelini repousando dentro das casas durante o dia. Portanto, parece que os mosquitos não vinham para descançar mas, sim, vinham ativamente para se alimentar.

As diferenças no ciclo de picadas poderiam ser o resultado das diferenças nas taxas de paridade dos Anophelini nas diferentes áreas. Neste caso, é possivel que os insetos nulíparos venham se alimentar antes de meia noite e os indivíduos multíparos venham depois da meia noite. Se a população do Uauaris fosse de mosquitos de idade avançada, então, esperar-se-ia que o pico da atividade de picada fosse mudado para a última metade da noite.

Mas é mais provável que, em uma área tão grande como a América do Sul, as populaçōes de $A$. darlingi sejam geográficamente isoladas uma das outras. Tal isolamento tenderá a produzir linhagens locais que sejam geneti- camente adaptadas às condições locais. Finalmente, espécies ou subespécies originar-se-ão deste tipo de situação. É possível que as diferenças no comportamento de picadas representem linhagens genéticas diferentes de mosquitos. Gabaldon et al, (1975) cita que o comportamento de repouso em casas de $A$. darlingi é, na metade sul da Venezuela, diferente do da metade norte. No norte os mosquitos repousam em casas durante o dia mas, no sul, os mosquitos são altamente exofilicos e não repousam nas paredes das casas o tempo suficiente para absorver doses de inseticidas. Esta diferença comportamental pode ser. também, resultados de uma variação genética entre as populações.

\section{ÀGRADECIMENTOS}

Gostaríamos de agradecer a Maria Regina Filgueiras dos Reis pela tradução do manuscrito, e também ao T. J. Wilkes pela leitura crítica do mesmo.

\section{SUMMARY}

The biting behaviour of Anopheles darlingi Root from three areas in Brasil is compared and differences in the biting cycle are discussed.

Dividson, G.

\section{BIBLIOGRAFIA CITADA}

1974 - Genetic control of insect pests. Academic pres. ix, $158 \mathrm{p}$.

FORATTINI, O. P.

1962 - Entomologia médica. São Paulo, Ed. Universidade de São Paulo, v 1, 662 p.

Gabaldon, A.; Garcia, M. G. \& Sifontes, R.

1975 - Necessidades en el campo de la investigación del programa Nacional de Erradicación y control de la Malaria de Venezuela. Bol. Dir. Malar. Amb., 15(6) : 264-285.

Hayes, J.; Charlwood, J. D.

1978 - Dinâmica estacional de uma população de Anopheles darlingi numa área endêmica de malaria no Amazonas. Acta Amazonica (no prelo).

SCORZA, J. V.; TAllaferro, E. \& Rubiano, H.

1976 - Comportiamento y susceptibilidade de Anopheles nunéz-tovarie Gabaldon 1940 a la infección con Plasmodium falciparum y Plasmodium vivax. Bol. Dir. Malar. San Amb., 16(2) : 129-136.

WRIGHT, J. W. \& PAL, R. eds.

1967 - Genetics of insect vectors of disease. Amsterdan, Elsevier. p. 211-250.

(Aceito para publicaçăo em 19/07/78) 